\section{The importance of hematocrit for oxygen delivery and hemodynamics}

\author{
Francesco Nicosia, ${ }^{1}$ Francesco Savelli, \\ Raffaella Di Luzio, ${ }^{3}$ \\ Federico Lari, ${ }^{4}$ Fabrizio Giostra, ${ }^{5}$ \\ Nicola Di Battista ${ }^{3}$
}

${ }^{1}$ Faculty of Medicine and Surgery, Magna

Graecia University of Catanzaro;

${ }^{2}$ Emergency-Urgency Medicine, Faenza -

Ravenna Local Health Unit; ${ }^{3}$ General

Medicine, IRCSS Rizzoli Orthopedic

Institute; ${ }^{4}$ Department of Internal

Medicine, San Giovanni in Persiceto

Hospital; ${ }^{5}$ Emergency Medicine

Department, S. Orsola Malpighi -

University Hospital, Bologna, Italy

\section{Abstract}

Anemia is common in elderly patients undergoing surgery and in critical patients. A 72-year-old man submitted to a revision of hip replacement implant was diagnosed with tuberculosis, followed by pulmonary fibrosis, pulmonary heart disease and compensatory erythrocytosis. In the postoperative period, he got anemia which improved his clinical status. Anemia reduces viscosity, i.e. one of the components of vascular resistance to laminar (according to the law of Hagen-Poiseuille) and turbulent flows. In conditions of decreased hematocrit, shear thinning occurs more easily and in larger caliber vessels. Hemodiluition reduces both right and left cardiac afterloads, thus provoking an improvement of the blood flow. As the hematocrit decreases, oxygen delivery increases, because the increase in the cardiac output is greater than the decrease in the concentration of hemoglobin. Further studies are needed to confirm this physical model and to establish the variable and degree of the transfusion trigger.

\section{Introduction}

Anemia is common in elderly patients undergoing surgery and in critical patients.

Anemia is defined as the reduction of blood oxygen-binding ability; it is function of the total number of red blood cells (RBCs), so it is commonly defined as a decrease in number of RBCs. ${ }^{2}$ The prevalence of preoperative anemia fluctuates from $5.4 \%$ to $38.0 \%$ and it reaches up to $29 \%$ in intensive care unit (ICU) patients having hemoglobin concentration less than the normal range at admission. ${ }^{3}$
However, it is unclear whether and how degree preoperative anemia influences postoperative mortality. ${ }^{4}$ Moreover, the consequences of anemia on morbidity and mortality in the critically ill patient are poorly defined. ${ }^{3}$

In this paper, we present a case in which the reduction of red blood cells from 6.5 to $3.65 \times 10^{12} / \mathrm{L}$ has improved the clinical status of the patient.

\section{Case Report}

A 72-year-old man, previously submitted to a hip replacement surgery, was admitted to our hospital to revise his hip replacement implant. When he was young, he had been diagnosed with tuberculosis, followed by pulmonary fibrosis. Subsequently, he had developed pulmonary heart disease and compensatory erythrocytosis, resulting in tissue hypoxia.

At the time of admission, laboratory test results revealed hemoglobin $(\mathrm{Hb}) 18 \mathrm{~g} / \mathrm{dL}, \mathrm{RBC}$ $6.5 \times 10^{12} / \mathrm{L}$ and hematocrit $57 \%$. At rest, he showed pulse oximeter oxygen saturation $\left(\mathrm{SpO}_{2}\right)$ of $90-91 \%$ breathing ambient air, and tissue oxygen saturation $\left(\mathrm{StO}_{2}\right)$ of $75-77 \%$. After stress, $\mathrm{SpO}_{2}$ decreased to $83 \%$, and recovered slowly; $\mathrm{StO}_{2}$ decreased to $67 \%$ and recovered faster. These clinical features considered, microvascular oxygenation, microvascular blood flow, bleeding, and transfusion had to be carefully cared for during surgery. In the immediate post-operatory course, the patient was recovered in intensive treatment unit. Pulse oximeter oxygen saturation was $98 \%$ and $\mathrm{StO}_{2}$ was $77 \%$ with continuous positive airway pressure (CPAP) and Ventimask ${ }^{\circledR}$; Hb concentration was $9.5 \mathrm{~g} / \mathrm{dL}$, with 1 red blood cell units transfused.

The following days, the patient was transferred to the hospital ward. Pulse oximeter oxygen saturation was $95 \%$ and $\mathrm{StO}_{2}$ was $77 \%$, supported by oxygen therapy with nasal cannula at oxygen flow of $2 \mathrm{~L} / \mathrm{min}$. Blood laboratory tests revealed levels of $\mathrm{Hb}$ concentration of 11 $\mathrm{g} / \mathrm{dL}$, RBC $3.65 \times 10^{12} / \mathrm{L}$, and hematocrit $32 \%$.

Although blood oxygen-binding ability reduced in this new rheological condition, the patient felt well, even better than before surgery. His hemodynamic condition was not worsened as we might have expected taking into consideration the effects of the anemization on arterial oxygen content $\left(\mathrm{CaO}_{2}\right)$.

\section{Discussion}

The present case illustrates the importance of blood features for hemodynamics. In order to elucidate the phenomenon, we maintain
Correspondence: Federico Lari, Department of Internal Medicine, San Giovanni in Persiceto Hospital, San Giovanni in Persiceto, Italy. Tel. +39.051.6225111 - Fax: +39.051.6584923.

E-mail: larifede@yahoo.it

Key words: anemia, hematocrit, viscosity, shear thinning, oxygen delivery.

Contributions: the authors contributed equally.

Conflict of interests: the authors declare no potential conflict of interests.

Received for publication: 15 February 2013.

Accepted for publication: 11 April 2013.

This work is licensed under a Creative Commons Attribution 3.0 License (by-nc 3.0).

(C) Copyright F. Nicosia et al., 2013

Licensee PAGEPress, Italy

Emergency Care Journal 2013; 9:e4

doi:10.4081/ecj.2013.e4

that the hydrodynamic laws regulating the blood flow must be analyzed. The flow of a fluid through a conduit can be explained by the hydraulic analogy of the Ohm's law. Ohm's law states that the flow of electrical charges through a conductor between two points is directly proportional to the potential difference across the two points, and inversely proportional to the electrical resistance. Similarly, the flow of a fluid through a conduit depends on the pressure gradient at the ends of the ducts and on the vascular resistance to the flow, due to the resistance to the constant flow and the resistance to the change of the flow. ${ }^{5}$

The main determinants of resistance to laminar flow were determined by Hagen and Poiseuille, who arrived at the mathematical equation that describes this relationship:

$$
\mathrm{Q}=\left(\mathrm{DP} \mathrm{p} \mathrm{r}^{4}\right) /(8 \mathrm{~L} \mathrm{~m})
$$

where: $Q$ is the volumetric flow rate; DP is the pressure drop; $p$ is the mathematical constant $\mathrm{Pi}$; $\mathrm{r}$ is the radius of the conduct; $\mathrm{L}$ is the length of the pipe; and $\mathrm{m}$ is the dynamic viscosity. ${ }^{6}$

The turbulent flow (Reynolds number $>2300$ ) is associated with a non-linear relationship between pressure and flow, dependent primarily on the viscosity of the fluid. ${ }^{7}$

Hematocrit is the main determinant of blood viscosity $(\mathrm{m})^{8}$ and a reduction in the hematocrit decreases the denominator of the Poiseuille-Hegan law, thus increasing blood flow (Q).

Moreover, blood is not a Newtonian fluid, but, from a rheological point of view, it is considered a suspension of cells in a homoge- 
neous fluid. The corpuscular part and the serum are moving at different rate flows. In small-caliber distal vessels, plasma flows more easily, so in these vessels the relative plasma volume increases, the relative viscosity decreases and the flow is facilitated. This phenomenon is called shear thinning. In conditions of decreased hematocrit, it occurs more easily and in larger caliber vessels; therefore, the flow rate increases in a greater area of the vascular bed. ${ }^{9}$

Oxygen delivery $\left(\mathrm{DO}_{2}\right)$ is the amount of oxygen delivered to the whole body from the lungs. ${ }^{7}$ It is the product of total blood flow and the oxygen content of arterial blood, directly dependent on $\mathrm{Hb}$. Hemoglobin is directly proportional to $\mathrm{DO}_{2}$, so as $\mathrm{Hb}$ reduces, $\mathrm{Hb}$ decreases as well. Nevertheless, it has been shown that the progressive hematocrit decrease is associated with a steady increase in cardiac output, with a slope proportionately greater than expected for the inverse proportionality. ${ }^{10}$ This response is attributable to the dependence of viscosity on the flow rate. Euvolemic hemodilution remarkably reduces both right and left cardiac afterloads, as they share blood features.

Analyzing the trend of the $\mathrm{DO}_{2}$ with varying hematocrit, there is evidence ${ }^{11}$ that the zenith of the curve occurs for a hematocrit value of $30 \%$. For this to happen, it is essential an adequate cardiac functional reserve, because the increase in the $\mathrm{DO}_{2}$ is subordinated to the increase in cardiac output under conditions of reduced afterload. ${ }^{12}$ Reducing the hematocrit from 45 to $30 \%$, the $\mathrm{DO}_{2}$ augments because the increase in the cardiac output is greater than the decrease in $\mathrm{Hb}$ concentration. Further reductions of hematocrit decrease the $\mathrm{DO}_{2}$ because they reduce $\mathrm{Hb}$, and a further increase in blood flow is unable to compensate this reduction. In more advanced stages, the inadequate supply of $\mathrm{O}_{2}$ to the heart limits the increase in blood flow.

\section{Conclusions}

We reported a case of euvolemic anemia that improves clinical conditions. This effect is due to hemodiluition that reduces both right and left cardiac afterloads, thus provoking an improvement of the blood flow.

This explanation can justify the evidence that a high degree of anemia can be well tolerated and that the morbidity and the mortality do not increase until $\mathrm{Hb}$ levels reach values lower than $7 \mathrm{~g} / \mathrm{dL}^{13}$ (up to $4.5 \mathrm{~g} / \mathrm{dL}$ ). ${ }^{14} \mathrm{~A}$ Carson's systematic review ${ }^{15}$ and the Triiodothyronine for Infants and Children Undergoing Cardiopulmonary Bypass (TRICC) trial ${ }^{16}$ have shown a reduction in 30 -day mortality with restrictive transfusion strategy compared to the group with bountiful indication for transfusion.

Further studies are needed to comfirm this physical model and to establish the variable and the degree of the transfusion trigger.

\section{References}

1. Jansson S. [Anemia a common diagnosis in elderly. How low can the $\mathrm{Hb}$ value be?]. [Article in Swedish]. Lakartidningen 2009;106:189-90.

2. Marino PL, Conti G, Gattinoni L. The ICU book. Terapia intensiva. Principi fondamentali. 3rd ed. Paris: Elsevier-Masson; 2007.

3. Vincent JL, Baron JF. Anemia and blood transfusion in critically ill patients. JAMAJ Am Med Assoc 2002;288:1499-507.

4. Greenky M, Gandhi K, Pulido L, et al. Preoperative anemia in total joint arthroplasty: is it associated with periprosthetic joint infection? Clin Orthop Relat $\mathrm{R}$ 2012;470:2695-701.

5. Guyton A, Hall J. Overview of the circulation; medical physics of pressure, flow, and resistance. In: Gruliow R, ed. Textbook of medical physiology. 11th ed. Philadelphia, PA: Elsevier; 2006. p 164.

6. Mortensen NA, Okkels F, Bruus $\mathrm{H}$. Reexamination of Hagen-Poiseuille flow: shape dependence of the hydraulic resistance in microchannels. Phys Rev E 2005;71:057301.

7. Fink MP, Abraham E, Vincent J-L, et al. Terapia intensiva. 5th ed. Paris: ElsevierMasson; 2007.

8. Lowe GD. Blood rheology in vitro and in vivo. Baillieres Clin Haematol 1987;1:597636.

9. Lipowsky HH, Usami S, Chien S. In vivo measurements of "apparent viscosity" and microvessel hematocrit in the mesentery of the cat. Microvasc Res 1980;19:297-319.

10. LeVeen HH, Ip M, Ahmed N, et al. Lowering blood viscosity to overcome vascular resistance. Surg Gynecol Obstet 1980;150: 139-49.

11. Wilkerson DK, Rosen AL, Gould SA, et al. Oxygen extraction ratio: a valid indicator of myocardial metabolism in anemia. $\mathrm{J}$ Surg Res 1987;42:629-34.

12. Carson JL. Effect of anaemia and cardiovascular disease on surgical mortality and morbidity. Lancet 1996;348:1055-60.

13. Barash PG, Cullen BF, Stoelting RK, et al. Anestesia Clinica. 6th ed. Roma: Delfino Ed.; 2012.

14. Alexiu 0, Mircea N, Balaban M, Furtunescu B. Gastro-intestinal haemorrhage from peptic ulcer: an evaluation of bloodless transfusion and early surgery. Anaesthesia 1975;30:609-15.

15. Carson JL, Hill S, Carless P, et al. Transfusion triggers: a systematic review of the literature. Transfus Med Rev 2002;16:187-99.

16. Hebert PC, Wells G, Blajchman MA, et al. A multicenter, randomized, controlled clinical trial of transfusion requirements in critical care. New Engl J Med 1999;340: 409-17. 